Hegemonia - Revista Eletrônica do Centro Universitário Euro-Americano

ISSN: 1809-1261

UNIEURO, Brasília, número 30, Julho-Dezembro de 2020, p. 104-131.

\title{
DIREITOS HUMANOS, CIDADANIA E ESTADO \\ MEDIANTE A GLOBALIZAÇÃO
}

\section{THE EFFECTS OF GLOBALIZATION IN HUMAN RIGHTS, CITIZENSHIP AND THE STATE}

\author{
Henry Ani Kifordu ${ }^{1}$
}

\begin{abstract}
RESUMO
O trabalho visa examinar os possíveis nexos entre os direitos humanos (com a cidadania) e o Estado mediante o ímpeto crescente da globalização. Enquanto a maioria dos estudos foca a relação natural entre a globalização e o crescimento econômico, esse trabalho diverge-se e inclina-se atenção teórica e analítica no enriquecimento da literatura sobre os efeitos da globalização na sustentação e promoção dos direitos humanos e cidadania constitutiva. Indaga-se: de que forma a globalização restringe a capacidade soberana do Estado na sustentação e promoção dos direitos humanos com a cidadania, em especial nos países em desenvolvimento como Brasil? Parte-se da conjectura de que a globalização, norteada pelo neoliberalismo e reforçada institucionalmente pelo Consenso de Washington, tem atuado no sentido de erodir ou, ao menos, conter a capacidade soberana do Estado para proteger e promover os direitos fundamentais, inclusive, os tocantes à cidadania. As observações, tanto em nível teórico - analítico quanto experiencial, atestam para a fragilidade e passividade do Estado mediante o ímpeto globalizante. Salvo as condutas idiossincráticas das elites governantes, os direitos humanos junto com a cidadania estão sendo sufocados devido à constrição da soberania do Estado, por sua vez, provocada pela 'avalanche' globalizante.
\end{abstract}

Palavras-chave: Direitos Humanos. Cidadania. Globalização. Estado

\footnotetext{
${ }^{1}$ Universidade de Brasília. Brasil. E-mail: hkifs@yahoo.co.uk
} 
Hegemonia - Revista Eletrônica do Centro Universitário Euro-Americano

ISSN: 1809-1261

UNIEURO, Brasília, número 30, Julho-Dezembro de 2020, p. 104-131.

\begin{abstract}
This piece of work examines the possible links between human rights and the State amid the current forces of globalization. While most studies focus attention in the natural relationship between globalization and economic growth, this work differs and inclines theoretical and analytical attention on the effects of globalization on the sovereign capacity of the State to respect and promote human rights with its constitutive citizenship. The question is: To what extent does globalization restrict the sovereign capacity of the State to sustain and promote human rights with citizenship in developing countries, especially Brazil? It is conjectured that globalization, guided by neoliberal precepts and institutionally reinforced by the Washington Consensus, advances, particularly in developing countries such as Brazil, to the detriment of sustaining and promoting human rights and citizenship. The observations, based on theoretical, analytical and experiential findings, attest the fragility and passivity of the state amid the active forces of globalization. Save the idiosyncratic conducts of the governing elites, Human rights with its constitutive citizenship rights are being impaired due to the weakening of state sovereignty, in turn, provoked by the globalization 'avalanche'.
\end{abstract}

Keywords: Human rights. Citizenship. Globalization. State.

\title{
INTRODUÇÃO
}

O objetivo desse trabalho é examinar as possíveis relações entre direitos humanos, cidadania e Estado mediante o ímpeto crescente da globalização. Procura-se discorrer sobre a forma que a globalização, ancorada no neoliberalismo e prenunciada pelo Consenso de Washington, implique em erosão ou contenção da capacidade do Estado para prover e proteger direitos fundamentais, inclusive os tocantes à cidadania como componente essencial dos últimos. Apesar da hodierna e esporádica emergência das lideranças políticas conservadoras ligadas à assim chamada extrema direita com condutas tendentes à restrição dos direitos humanos e da atual pandemia inibidora de interações físicas pelas fronteiras internacionais, a globalização perdura.

Ainda, a despeito de que, em tempos e contextos variados, o mundo havia experimentado certo grau de globalização antes dos anos 80 , o processo atual se ergue de forma mais marcante e abarcante em termos de suas características e amplitude num mundo bem mais complexo. Na esteira dos 75 anos da declaração dos Direitos Humanos, ou seja, desprovido pouco mais de um quarto século do centenário, convém à pergunta: 
Hegemonia - Revista Eletrônica do Centro Universitário Euro-Americano

ISSN: 1809-1261

UNIEURO, Brasília, número 30, Julho-Dezembro de 2020, p. 104-131.

de que forma a globalização impacta na capacidade do Estado para prover e assegurar direitos bem consagradores da humanidade?

O estudo é motivado pela carência de literatura ressaltante e crítica da conectividade entre fenômenos tão recorrentes e preocupantes quanto àqueles relativos a direitos humanos, cidadania e Estado mediante o processo globalizante. Igualmente, a atual globalização se impõe e ganha ímpeto num contexto político internacional antecedido pelo Estado moderno, por sua vez conhecido pelo culto à soberania. Ao menos em tese, a soberania subentende uma capacidade superior do Estado ou de seus dirigentes para zelar pelos interesses sociais, inclusive a garantia dos direitos humanos com a cidadania, sem interferências externas. A forma que essa cominação e afoiteza globalizante impactam nos destinos e, mais premente, na capacidade de atuação do poder estatal vis-à-vis necessidades de proteção social continua a agitar debates acadêmicos e políticos.

Diferente da relação frequentemente salientada entre globalização econômica e democracia no seu sentido mais amplo, o nexo entre globalização, diretos humanos e cidadania é pouco estudado criticamente. A forma que a globalização restrinja o escopo das políticas públicas voltadas para promoção dos direitos fundamentais nos países em desenvolvimento, em particular, no Brasil, é uma preocupação crescente. De interesse maior é a questão da erosão do poder soberano dos Estados-nações pela crescente força propulsora da interconectividade mundial.

O ponto de notável atenção é que o poder estatal para promover direitos humanos e cidadania passa pelos instrumentos de controle político, econômico, cultural e social à sua disposição. Quando o Estado é pressionado, como vem ocorrendo nas últimas décadas, para cortar profundamente as despesas, em especial nas áreas sociais, mirando, por exemplo, a privatização das empresas públicas, existe efeitos sociais e econômicos, em formas de renúncia aos direitos sociais e econômicos devido à perda do emprego e emergência de ociosidade lesiva à cidadania. Nesse sentido, convém a seguinte pergunta. De que forma a globalização restringe a promoção dos direitos humanos com a cidadania pelo Estado-nação, em especial nos países em desenvolvimento como Brasil? 
Hegemonia - Revista Eletrônica do Centro Universitário Euro-Americano

ISSN: 1809-1261

UNIEURO, Brasília, número 30, Julho-Dezembro de 2020, p. 104-131.

Contesta-se que nos países ditos em desenvolvimento, como Brasil, a globalização corrente, deflagrada nos anos 80 , calcada nas ideias neoliberais e reforçada institucionalmente pelo Consenso de Washington, tem coeteris paribus restrita a promoção mais realista dos direitos humanos e da cidadania prevista nestes últimos. Ao atuar no sentido de desmantelar as barreiras contra o livre mercado, mediante avanço tecnológico, a atual interconectividade mundial contrai a capacidade do Estado-nação para tomar decisões de forma autônoma e voltada para proteger e promover os direitos humanos através das políticas públicas. A globalização atua no sentido de abrandar a força soberana do Estado-nação para promover os direitos individuais e coletivos. Além da globalização como força externa, os direitos humanos sofrem novos reveses pela emergência interna de líderes políticos ditos conservadores, populistas e nacionalistas da extrema direita.

Para esclarecer o sentido da relação entre a globalização, direitos humanos e cidadania nos países em desenvolvimento, assume-se no trabalho uma postura crítica, pois, estes últimos ostentam estruturas econômicas, políticas e sociais relativamente vulneráveis. A vulnerabilidade implicaria a princípio em assimetria de condições estruturais e na dificuldade maior dos respectivos Estados para se adaptarem e corresponderem às mudanças decorrentes das exigências globalizantes.

$\mathrm{O}$ trabalho se reparte em quatro partes. $\mathrm{Na}$ primeira, será qualificada a globalização como variante causal cujo ímpeto decorre das ideias tanto liberal quanto neoliberal subsequente, e do Consenso de Washington. Enquanto as ideias liberal e neoliberal são analisadas como sustentáculos ideológicos da globalização, o Consenso de Washington será focado em termos de um recurso institucional norteador do processo. Para tanto, servem como conceitos e arcabouço teórico-analíticos da globalização. $\mathrm{Na}$ segunda parte, será abordado o Estado mediante a globalização, mostrando a forma como a constrição da barreira nacional e a autoridade estatal se dão com o avanço da globalização. Na terceira, os direitos humanos e a globalização serão transpostos para ilustrar o quanto cabe ao Estado proteger os Direitos Humanos notadamente contra os impactos negativos da globalização. Na quarta e última parte antes da conclusão, a atenção se volta ao Brasil e Direitos Humanos mediante a globalização. Busca-se com 
Hegemonia - Revista Eletrônica do Centro Universitário Euro-Americano

ISSN: 1809-1261

UNIEURO, Brasília, número 30, Julho-Dezembro de 2020, p. 104-131.

base em recortes literários e pesquisa sobre empregabilidade da mão-de-obra das empresas privatizadas em decorrência da globalização e suas ancoras neoliberal e Consenso de Washington, trazer à tona e criticamente uma das formas que a globalização inibe a promoção dos direitos humanos ao sufocar a capacidade estatal.

\section{GLOBALIZAÇÃO: SUBPRODUTO DO NEOLIBERALISMO E CONSENSO DE WASHINGTON}

Antes de abordar a questão da globalização e seu nexo com direitos humanos e cidadania como elemento constitutivo, convém uma discussão informativa do neoliberalismo e Consenso de Washington - duas forças motrizes que juntas, interligadas e ativadas fizeram nascer a globalização, dando-lhe o sentido desejado.

\subsection{Neoliberalismo}

Existem várias abordagens conceptuais tanto convencionais quanto críticas sobre o neoliberalismo. De antemão, vale ressaltar a coexistência de vertentes conceptuais que em um lado atribui ao neoliberalismo sentido teórico-pragmático e, noutro, significado ideológico-doutrinário. Não obstante, como a preocupação central do trabalho não abarca as divergências acerca dos aspectos semânticos do neoliberalismo, mas sua inspiração vis-à-vis a globalização, convém um entendimento mínimo consistente com o tema do trabalho. Para os efeitos analítico-comparativos, será apenas discernir entre os argumentos convencionais que balizam neoliberalismo e aqueles que o contrapõem criticamente.

Os adeptos do neoliberalismo asseguram que este seja menos ideológico do que retratado pelos seus oponentes. Thorston e Lie consideram o neoliberalismo a versão reavida do liberalismo, uma vez que tudo sugira seu renascimento em função da decadência do último. Se o liberalismo envolve a crença no Estado mínimo, ou seja, aquele limitado às funções básicas tais como a manutenção das forças armadas, policiamento, e outros bens não excludentes, o neoliberalismo, retratado numa 
Hegemonia - Revista Eletrônica do Centro Universitário Euro-Americano

ISSN: 1809-1261

UNIEURO, Brasília, número 30, Julho-Dezembro de 2020, p. 104-131.

abordagem histórica, é uma teoria de práticas da política econômica que propõe a libertação da livre iniciativa e das habilidades como melhor forma de avançar o bem estar social dentro de um arcabouço institucional caracterizado pelo direito substancial de propriedade privada com mercado e comércio livre (Online 2006).

Fundamental no entendimento sobre as atenuações ideológicas do neoliberalismo é o característico papel do Estado que, ao contrário do Estado mínimo liberal, amplia-se na área social, mas, sem excessos. Além de "criar e preservar um arcabouço institucional apropriado para" as práticas do mercado e comércio livre, o Estado assume o dever de assegurar, por exemplo, a qualidade da moeda e estabelecer aquelas estruturas e funções militares, de defesa, policial e legais que são necessárias para assegurar a propriedade privada e garantir, se for preciso pela força, o funcionamento adequado do mercado (Harvey 2005:2). Nesse aspecto, afirma que:

Se o mercado não existisse (nas áreas tais como terra, água, educação, saúde, segurança social ou poluição ambiental) então devem ser criados pela ação do Estado. Mas, além desses objetivos, o Estado não deveria aventurar. A intervenção do Estado no mercado (uma vez criada) deve ser mantida a um mínimo raro, pois de acordo com a teoria, o Estado não pode possivelmente ter informação suficiente para adivinhar de antemão os sinais de mercado (preços) e porque os interesses de grupos poderosos distorcerão e aviesarão a intervenção do Estado (particularmente nas democracias) para seus próprios benefícios.

Um entendimento mais incisivo do significado do neoliberalismo remete a discussão às ideias originárias de seus expoentes máximos contemporâneos. Foi Hayek, economista austríaco e teórico social, quem, apesar de advogar por uma intervenção mínima do Estado, vê no mercado o único meio de coordenar as decisões e ações humanas numa base social condutiva à eficiência e liberdade (1990).

Mais tarde, Friedman, economista norte americano e integrante da escola de Chicago, EUA, e da Sociedade de Mont Pelérin, fundada por Hayek na Suíça para oporse a qualquer princípio de planejamento central, propagar a ideia e propor a prática de mercado, relata em seu livro, Capitalismo e Liberdade, o que seria as funções do Estado nos governos liberais como sendo: a manutenção da lei e ordem; a definição e ajuste das leis de propriedade e outras regras do jogo econômico; o julgamento de disputas sobre a interpretação das regras, o reforço dos contratos, promoção da competição; fornecimento de uma estrutura monetária, eliminação dos efeitos julgados suficientes para justificar 
Hegemonia - Revista Eletrônica do Centro Universitário Euro-Americano

ISSN: 1809-1261

UNIEURO, Brasília, número 30, Julho-Dezembro de 2020, p. 104-131.

intervenção do Estado, suplementação da caridade privada e familiar na proteção do irresponsável (1985).

Enfim, o neoliberalismo, ao propor a livre iniciativa no mercado livre e limitar substancialmente o papel do Estado, criou as bases econômicas e políticas para a globalização. Sem essas bases, subsequentemente apoiadas no Consenso de Washington, a globalização perderia a orientação indispensável. Mas, nem todos com razão acenam favoravelmente às opulentas propostas neoliberais de atender aos problemas sociais pelas livres forças de mercado considerados inadmissíveis à intervenção do Estado. Críticos apontam para os efeitos inconsequentes de sua aplicação mediante a ausência significativa do Estado em apoiar investimentos periódicos, os quais contribuem para regular as falhas do mercado.

Num estudo apoiado em dados empíricos, Kotz (2000) mostra que "o modelo neoliberal não promova acumulação rápida”, pois suscita tantos problemas econômicos quanto sociais. O modelo neoliberal é ressaltado como aquele com forte tendência para gerar demanda agregada insuficiente no longo prazo, uma vez que amaine salários reais e despesas públicas, crie instabilidade em nível macroeconômico ao renunciar as despesas públicas, essencialmente aquelas contracíclicas, e as políticas tributárias, e afrouxe a regulação do setor financeiro. Isso, denuncia, faz com que o sistema se torne mais vulnerável às grandes crises e depressões. Além demais, o modelo neoliberal tende a intensificar o conflito de classe, que pode potencialmente desestimular o investimento de capital (p. 3).

Se o modelo neoliberal restringe o escopo da acumulação do capital privado, terá um efeito redutor na capacidade fiscal e financeira do Estado. Antes mesmo da deflagração da atual pandemia, o desemprego já se encontrava com taxas altas como reflexo da queda da atividade econômica e da deficiente alocação de recursos econômicos. O advento da pandemia só fez agravar a situação. Ademais, em muitos países ditos em desenvolvimento, especialmente Brasil, a desigualdade social acentuada já fazia e continua fazendo presente na estrutura social. Como efeito nada positivo, muitos cidadãos se encontram incapacitados de acessar e participar no livre mercado seja como consumidor ou produtor. 
Hegemonia - Revista Eletrônica do Centro Universitário Euro-Americano

ISSN: 1809-1261

UNIEURO, Brasília, número 30, Julho-Dezembro de 2020, p. 104-131.

A implicação mais relevante dessa perspectiva econômica e política é que ao limitar a capacidade do Estado para despender recursos em prol de investimentos públicos ou subsidiar a produção empresarial, visando promover as demandas agregadas através da melhoria da renda efetiva do trabalhador, surge problemas sociais oriundo de acesso limitado ao mercado e da mobilização sindical. Em última análise, enfraqueceria os direitos humanos e a cidadania, conforme serão delineados a seguir.

Após descrever criticamente neoliberalismo "como liberalismo econômico radical, [...] ideologia de Estado mínimo e mercados autorregulados”, Pereira (2009, p. 79) contesta a ideia associada aos neoliberais de que tanto a instituição do Estado quanto aquelas do mercado constituam alternativos. Fatalmente declara que:

Não faz sentido, então, opor-se ao Estado e mercado. [Pode-se] apontar problemas no Estado. [Pode-se] entender que certas atividades possam ser melhor coordenadas se o Estado limitasse sua regulação do mercado, mas [é] errada considerar ambas as formas de coordenação como alternativas, pois o Estado sempre regulará o mercado e porque a responsabilidade última pela boa ou má coordenação não será o mercado, desprovido de vontade própria, mas a sociedade - a qual, através das formas distintas da organização política (sociedade civil ou nação), constitui o Estado e, no Estado democrático, elege seu governo (p. 7).

Parece inconteste que Pereira (2009) esteja se referindo à tipologia do Estado cujas elites governantes são verdadeiramente responsáveis aos governados (ou seja, à sociedade como um todo). Nesse tipo de Estado, a regulação do mercado pelos agentes estatais, além de atividade complementar, é um papel vital para promover, num lado, o funcionamento efetivo do mercado e, noutro, a inclusão social que por extensão opera para assegurar os direitos humanos e a cidadania que, além de obrigação, outorgue a titularidade de direito.

Uma das críticas mais contundentes, talvez a mais contumaz, ao neoliberalismo, cujos adeptos dos centros avançados do capitalismo mundial enfatizam o mercado aberto com Estado mínimo, surge não de marxistas ou neomarxistas mais incólumes, mas de Ha - Joon Chang ${ }^{2}$ em seu livro; Kicking Away the Ladder: Development Strategy in

\footnotetext{
${ }^{2}$ Embora, classificado como economista heterodoxo e orientado por um marxista em sua tese de doutorado na Universidade de Cambridge, Inglaterra, Ha-Joon Chang, que nasceu na Correa do Sul e foi listado como um dos 20 maiores pensadores do mundo pela revista Prospect de 2013, não é um marxista ortodoxo no seu sentido clássico e integrante.
} 
Hegemonia - Revista Eletrônica do Centro Universitário Euro-Americano

ISSN: 1809-1261

UNIEURO, Brasília, número 30, Julho-Dezembro de 2020, p. 104-131.

Historical Perspectives (Chutando a Escada: A Estratégia do Desenvolvimento em Perspectiva Histórica) lançado em 2002. O autor argumenta que os países desenvolvidos, que hoje exigem medidas ortodoxas para os países desenvolvidos, não avançaram, em termos de seus altos níveis de desenvolvimento socioeconômico, através de políticas e instituições que agora recomendam para os países em desenvolvimento. Ao se referir criticamente às prescrições do Consenso de Washington, observou que o mundo desenvolvido com seu establishment ${ }^{3}$ da política internacional de desenvolvimento que controla tenha recorrido às medidas protetivas, assim, não perseguiu o tipo de políticas neoliberais macroeconômicas e estruturais robustas que hoje prescrevem para os países em desenvolvimento (2003/2007, p. 2-3).

Não obstante, e ao contrário do imperativo liberal clássico restritivo do papel do Estado na sociedade, especialmente, na economia, atribuindo a essa última o papel de produzir e/ou fornecer os bens e serviços úteis como educação, saúde e infraestrutura (transporte e comunicação), o neoliberalismo acende uma luz para investimentos estatais na área social, isto é, na produção de serviços de apoio ao mercado. Porém, o Estado deve retirar-se assim que a necessidade social do setor se encontre satisfeita. No entanto, tanto a globalização quanto o Consenso de Washington, em suas orientações ou preceitos, não parecem conceder folga suficiente ao Estado no tocante à sua capacidade para fomentar os direitos fundamentais sem frear a primeira. Pois, enquanto a globalização avança com inovações técnicas e mudanças culturais atípicas que descaracterizam a força de trabalho local, o Consenso de Washington pede ajustes fiscais apertadíssimos e coibentes de investimentos sociais.

\subsection{Consenso de Washington}

Apesar das interpretações variadas e críticas, o Consenso de Washington permanece tanto como sustentáculo quanto afinador da política neoliberal, e atua ao

\footnotetext{
${ }^{3}$ A designação em inglês se refere ao grupo sociopolítico que exerce autoridade, controle ou influência dominante, defendendo seus privilégios numa ordem estabelecida. Pode significar a elite social, econômica e política de um país ou a ordem ideológica, econômica, política e legal por ela estabelecida numa sociedade ou num Estado.
} 
Hegemonia - Revista Eletrônica do Centro Universitário Euro-Americano

ISSN: 1809-1261

UNIEURO, Brasília, número 30, Julho-Dezembro de 2020, p. 104-131.

mesmo tempo para reforçar as instituições imprescindíveis à ativação do processo de globalização. Como pivô político, foi instrumental para animar as articulações iniciais entre a cúpula da elite (establishment) ${ }^{4}$ internacional, isto é, no âmbito do poder político internacional com sua manifesta assimetria. Originalmente elaborado por John Williamson como prescrição de políticas públicas na segunda metade de 1989, o Consenso de Washington contém uma lista inicial de reformas destinadas aos países latino-americanos.

Em linhas gerais, as 10 (dez) medidas são: 1) disciplina fiscal, através da qual o Estado deve restringir seus gastos à arrecadação, eliminando o déficit público; 2) mudança das prioridades em relação às despesas públicas, abolindo subsídios e aumentando gastos com saúde, educação e infraestrutura; 3) reforma tributária que amplie a base sobre a qual incide a carga tributária, atribuindo-se maior peso nos impostos indiretos e menor progressividade nos impostos direitos; 4) liberalização financeira, com o fim de restrições que impeçam instituições financeiras internacionais de atuarem em igualdade com as nacionais e o afastamento do Estado do setor, ou seja, remoção total de barreiras para que o mercado seja o critério de entrada e saída; 5) a taxa de câmbio deveria ser também determinada pelo mercado, garantindo-se ao mesmo tempo que fosse competitiva; 6) o comércio deveria ser liberalizado com redução de alíquotas de importação e estímulos à exportação, visando a impulsionar a globalização da economia - isto é, maior privilégio à liberalização dos fluxos de capitais; 7) a eliminação de restrições ao capital externo, permitindo investimento direito estrangeiro, ou seja, os investimentos diretos não deveriam sofrer restrições; 8) as empresas públicas deveriam ser privatizadas, o que implica na venda ou alienação das empresas de propriedade estatais; 9) as atividades econômicas deveriam ser desreguladas através da redução da legislação de controle do processo econômico e das relações trabalhistas e 10) o direito de propriedade intelectual deve ser tornado mais seguro ${ }^{5}$

\footnotetext{
${ }^{4}$ Refere-se à elite social, econômica e política de um país ou em nível internacional (como referida nesse trabalho) que apoiam a ordem ideológica, econômica, política e legal existente.

${ }^{5}$ Por mais detalhes sobre essas medidas vejam NEGRÃ̃O, João J. (1998) e PEREIRA (1991, p. 6 apud Williamson (1990, p. 8 -17) op cit.
} 
Hegemonia - Revista Eletrônica do Centro Universitário Euro-Americano

ISSN: 1809-1261

UNIEURO, Brasília, número 30, Julho-Dezembro de 2020, p. 104-131.

Ainda, nessa linha geral, o Consenso de Washington integra medidas práticas de contenção do tamanho do Estado (Estado mínimo) e liberalização do mercado (livre mercado). Fica claro que, nas intenções expressas pelas medidas do Consenso, sobressai a contenção dos gastos públicos. Curiosamente, persistem certas contradições nas propostas, tais vividas atualmente pelos Estados, em particular, os em desenvolvimento. Num lado, a redução dos gastos públicos mediante um rígido regime fiscal no qual inexistirá oposição, mas, sim, concordância, entre despesa e arrecadação, com a ampliação da base tributária e, noutro, ajustes nas prioridades do Estado vis-à-vis as despesas públicas, implicando a abolição dos subsídios e aumento dos gastos públicos em áreas sociais e econômicas fundamentais. Além de regulador, o Estado, especialmente, nos países em desenvolvimento, é um agente econômico consumidor e produtor bem como investidor. Sendo assim, circunscrever os gastos públicos à arrecadação, alargar arrecadação e retirar subsídios, apesar de seus efeitos equilibrantes do ponto de vista macroeconômico, não coadunam com o crescimento econômico, que, conforme visto, desabaria mediante a rigidez fiscal.

Da mesma forma que o neoliberalismo, o Consenso de Washington se processa e se procede, mas não sem críticas contundentes. Entre os críticos, destaca-se Stiglitz (2003), economista norte-americano, que primeiro alvejou o Fundo Monetário Internacional (FMI) ${ }^{6}$, uma Instituição Financeira Internacional (IFI) patrocinada pelos Estados hegemônicos internacionais e inspiradores, participantes e patrocinadores tanto do Consenso de Washington quanto do seu braço político - o neoliberalismo. O analista econômico norte americano rechaçou a forma exclusiva e unilinear da atuação do fundo que, além de ser dominado pelos países do $G 7^{7}$ que "controlam o poder de voto e as

\footnotetext{
${ }^{6}$ Criada na pós II Guerra Mundial e resultante da Conferência de Bretton Woods (1944), se propõe a promover a cooperação econômica internacional, o comércio internacional, o emprego e a estabilidade cambial, inclusive mediante a disponibilização de recursos financeiros para os países membros para ajudar no equilíbrio de suas balanças de pagamentos. Porém, por basear seu voto e controle acionário não na participação igualitária dos países signatários, mas em quotas oriundas da parcela das reservas internacionais dos 188 países membros, as políticas e os interesses visados pelas IFI acabam girando em torno dos países sócios mais ricos e hegemônicos.

${ }^{7}$ O Grupo dos Sete (G7) é um grupo internacional composto por: Alemanha, Canadá, Estados Unidos, França, Itália, Japão e Reino Unido, embora a União Europeia também esteja representada. Esses países são as sete economias mais avançadas do mundo, de acordo com o Fundo Monetário Internacional (FMI), os quais representam mais de $64 \%$ da riqueza líquida global, equivalente a 263 trilhões de dólares estadunidenses. Há críticas ao grupo por muitos movimentos sociais, normalmente integrados
} 
Hegemonia - Revista Eletrônica do Centro Universitário Euro-Americano

ISSN: 1809-1261

UNIEURO, Brasília, número 30, Julho-Dezembro de 2020, p. 104-131.

decisões (...), endossa o fundamentalismo do mercado" e carece de transparência e responsabilidade. Essas últimas transparecem nas operações do Fundo pela incorporação em seu processo apenas "os ministros da fazenda, os presidentes do Banco Central dos países [nele dependentes] e os que refletem as opiniões da comunidade financeira internacional", deixando de lado os governos nacionais com poder, autoridade e interatividade social para efetuar mudanças (STIGLITZ 2002:31-36) ${ }^{8}$.

A crítica de Stiglitz (2002) tem implicações sérias na segurança pública vis-àvis aplicação das diretrizes do fundo. Ao privilegiar a ação tecnocrática, relega-se a ação política, apesar dessa última exercer influência maior não somente sobre a consecução das decisões do fundo, mas sobre a variação da distribuição dos custos e benefícios sociais. A preterição da influência política nacional mediante o modus operandi do Fundo desprotege os cidadãos comuns, carentes de recursos para suportar as crises de austeridade provocadas por suas medidas ortodoxas. Por transcorrer num nível internacional de alocação de recursos financeiros, ser atrelado à expansão do mercado no mesmo nível e carecer de instrumentos políticos para efetuar as próprias mudanças almejadas, o Fundo precisou de um aval político moldado pelas potencias internacionais, justamente aquelas financiadoras e apoiadoras do Fundo. Toda essa engrenagem teve e continua tendo duas forças motrizes paralelas - Consenso de Washington e globalização.

\section{3. Globalização}

Existem várias abordagens da globalização, cujo processo desencadeou-se nos anos 80 , e às quais se atribui vários níveis e tipologias de efeitos econômicos, políticos, sociais e culturais. Em geral, globalização decorre da extensão e intensificação das atividades econômicas e da telecomunicação além das fronteiras nacionais. McGrew

no movimento antiglobalização, que o acusam de decidir uma grande parte das políticas globais, social e ecologicamente destrutivas, sem qualquer legitimidade nem transparência.

${ }^{8}$ Até o próprio Williamson (2004) reconhece que certos aspectos das críticas relativas às elaborações do Consenso têm limitações inoperantes. Veja Williamson, John (2004), "The Washington Consensus as Policy Prescription for Development". A lecture in the series "Practitioners of Development" delivered at the World Bank on January 13, 2004. 
Hegemonia - Revista Eletrônica do Centro Universitário Euro-Americano

ISSN: 1809-1261

UNIEURO, Brasília, número 30, Julho-Dezembro de 2020, p. 104-131.

define globalização em termos de dois tipos de interconectividade global paralela: num lado, tem-se o crescente número de bens e serviços, capital e pessoas circulando além das fronteiras nacionais e, noutro, a expansão mundial da tecnologia de comunicação em forma, por exemplo, de multimídia, constituindo-se em processo através dos quais "eventos, decisões e atividades que, desencadeadas numa parte do mundo, podem ter consequências para indivíduos e comunidades em partes distantes do globo" (1992:65). O paralelismo entre a difusão tecnológica e a circulação dos produtos além das fronteiras nacionais não simplesmente define a globalização, mas desperta atenção quanto aos seus impactos no domínio territorial e na respeitabilidade internacional desse domínio. Em particular, o domínio territorial enseja a capacidade que cada Estado detém por direito para tomar decisões que aparam a cidadania e, por extensão, fortalecem Estado-nação.

Baseada na ideia neoliberal, o entendimento gira em torno dos efeitos benéficos da abertura dos mercados nacionais tanto para o Estado quanto para a sociedade. Pamilsano (2006) ilustrou pela reputada revista Foreign Affairs sobre os efeitos positivos da globalização de que, ao propagar tecnologias compartilhadas e padrões de negócios, oportunidades sem precedentes de integração serão criadas, "não apenas dentro como entre cada sector da sociedade" (p. 135). Num estilo reminiscente da destruição criativa schumpeteriano, reiterou sobre esse impacto dualista:

[...] na medida em que as fronteiras entre os 'estados' tradicionais se tornem cada vez mais vulneráveis, novos negócios podem contribuir para novas formas de comércio, aprendizagem e boa governança. Líderes governamentais encontrarão no negócio parceiros desejosos para reformar a saúde e educação, assegurar os meios de comércio mundial e comércio eletrônico, treinar e capacitar os desabrigados e sem-terra, gerir os problemas ambientais e doenças infeciosas e encarar os outros desafios causados pela globalização.

Conhecimento de fato sobre o sentido dos efeitos da globalização exige pesquisas empíricas capazes de validar variações em investimentos, aculturação e mudanças sociais e políticas, especificamente inovações comerciais, adaptações e gestão. Não obstante, cabe a crítica pertinente de que sem considerar a relevância e sentido do jogo político, os globalistas simplesmente presumem decorrências opulentes da globalização para indivíduos, grupos e Estados.

Em Defesa da Globalização designa a obra de Jagdish (2007) que procurou destacar as posições favoráveis à globalização econômica e relevá-la como poderoso 
Hegemonia - Revista Eletrônica do Centro Universitário Euro-Americano

ISSN: 1809-1261

UNIEURO, Brasília, número 30, Julho-Dezembro de 2020, p. 104-131.

instrumento de desenvolvimento internacional, inclusive para os países taxados de mais pobres. Não obstante, o autor assinala a importância inter alia da boa gestão (governança) do processo econômico global, abstinência dos interesses hegemônicos por parte dos países desenvolvidos e restrição no fluxo internacional de recursos financeiros, apontando para a deficiência nas políticas públicas implementadas pelos países do sudoeste asiático e latino-americanos como motivação pelas crises financeiras experimentadas. In outros termos, o autor considerou culpável os países em desenvolvimento, não às assimetrias do livre comércio associado à globalização, pelos problemas econômicos e sociais que passam.

Ao reconhecer limites à abertura econômica e criticar as Instituições Financeiras Internacionais (IFIs) pelo irrestrito fluxo internacional de recursos financeiros aos países em desenvolvimento que, sem adequada estrutura econômico-financeira, os quebra na sequência de suas fugas disparadas (JAGDISH, 2007), acaba implicitamente admitindo contradições nos preceitos neoliberais que vem movendo a globalização. Mesmo se parte ou totalidade de certos países em desenvolvimento carece de políticas públicas socialmente efetivas, a fragilidade ou mesmo a ausência de mecanismos institucionais para frear os efeitos danosos da globalização é reflexo dos interesses que a movem e se escondem por trás das ideias e instituições moventes.

Para tanto, a globalização econômica, desenfreada e efusiva em seu avanço, acaba atuando para reforçar as condições estruturais e sociais adversas que os países em desenvolvimento enfrentam dentro dos respectivos confins. Esse avanço eminentemente supranacional e invariavelmente redutivo da soberania dos países em desenvolvimento, cumula, no sentido, não apenas de atrofiar a capacidade do Estado para promover direitos humanos, bem como de induzir os agentes públicos a reprimir, às vezes, com violência, as demandas por direitos humanos, especialmente, quando as pressões oriundas das forças globalizantes passam a desvirtuar as escolhas públicas, deixando os agentes públicos confusos ou acuados. 
Hegemonia - Revista Eletrônica do Centro Universitário Euro-Americano

ISSN: 1809-1261

UNIEURO, Brasília, número 30, Julho-Dezembro de 2020, p. 104-131.

\section{ESTADO MEDIANTE A GLOBALIZAÇÃO}

Independente dos benefícios putativamente arrogados à globalização, por sua vez, impulsionada pelo consenso de Washington, é inegável que, por ser tão desigual e variada a condição entre os Estados, sua fruição, se de fato tiver, não agrada a todos. Ademais, seu avanço, calcado nos preceitos neoliberais, não tem deixado agentes públicos dos países em desenvolvimento despreocupados com seus efeitos no sentido da capacidade tanto do livre mercado para arbitrar na alocação eficiente de recursos quanto do Estado para suprir os serviços sociais essenciais.

Axford (1997:481) retruca que "a implicação mais potente do processo de globalização é que a interconectividade global faz com que as fronteiras territoriais dos estados-nações estejam cada vez menos coincidentes com os padrões variantes da vida (..)". Essa observação tem desdobramentos importantes quanto aos efeitos perniciosos da globalização, especialmente para a sustentação da soberania do Estado, e, destarte, sua capacidade para desenvolver políticas públicas que fortaleçam os direitos humanos com a cidadania, como componente essencial.

Primeiro, a globalização restringe o escopo da autoridade política mais elevada do Estado, isto é, a soberania estatal ${ }^{9}$. A soberania no âmbito estatal deveria conservar o poder decisório do Estado, ou seja, da capacidade, sem restrições externas ou rivais internas, das elites governantes para tomarem decisões que afetam os vários segmentos da população que habita o território nacional, ou seja, Estado-nação.

\footnotetext{
${ }^{9}$ A soberania estatal é definida por Axford et al como "a ideia de autoridade política suprema" pela qual "inexiste poder mais ou menos alto" tanto interna quanto externamente (1997, p. 514). Assim, a soberania política deveria conservar a unidade interna sem interferências externas - o que a globalização pode negar.
} 
Hegemonia - Revista Eletrônica do Centro Universitário Euro-Americano

ISSN: 1809-1261

UNIEURO, Brasília, número 30, Julho-Dezembro de 2020, p. 104-131.

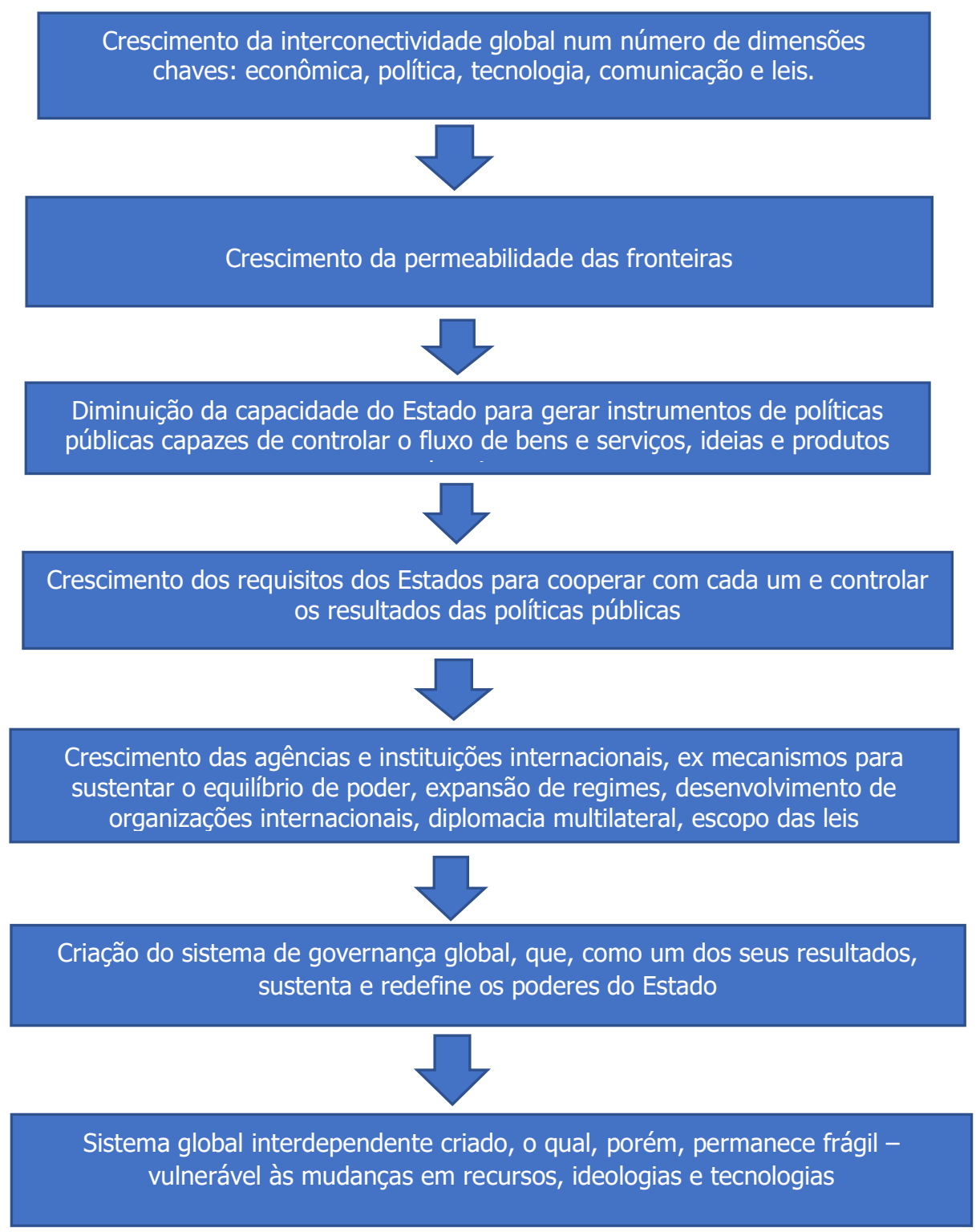

Figura 1: Mudanças na ordem internacional e a contradição entre Democracia, Estado-nação e Globalização. Fonte: (HELD, 1991, p. 209)

Held (1991) rebate a presunção de que "o Estado tem mantido controle sobre seus destinos, sujeito apenas aos compromissos que deveria fazer e aos limites impostos pelos atores, agências e forças operando em suas fronteiras territoriais" (1991, p. 203). Aponta para o problema das decisões tomadas por outros Estados-nações e outras organizações supranacionais [...] tais como FMI e Banco Mundial ou até mesmo empresas transnacionais que possam diminuir o escopo das decisões de uma dada maioria ou porque 
Hegemonia - Revista Eletrônica do Centro Universitário Euro-Americano

ISSN: 1809-1261

UNIEURO, Brasília, número 30, Julho-Dezembro de 2020, p. 104-131.

as decisões tomadas por uma maioria afetam ou têm potencial para afetar não apenas suas próprias.

A entrada e saída mais permissível das empresas transnacionais ou multinacionais, dotadas de altas tecnologias, produtoras de bens e serviços, além de serem apoiadas por outros Estados invariavelmente mais poderosos, denota poder econômico e social bastante atuante, o que pode implicar a diminuição da capacidade do Estado para efetuar governança através principalmente das próprias políticas públicas. Em segundo, ao restringir a autonomia e poder decisório do Estado-nação, a globalização pode tornar a promoção ou até mesmo sustentação do nexo positivo entre democracia, direitos humanos e cidadania mais difícil.

Num lado, Held (1991) afirma sobre o paralelismo entre a tomada de decisões majoritárias baseadas na democracia e as mudanças na ordem internacional pela globalização e, noutro, a contradição entre a proclamação global da democracia e o "comprometimento da viabilidade dos Estados - nações independentes" pela nova ordem internacional (p. 8). A figura 1 (acima), inspirado do trabalho de Held (1991), mostra a sequência desse paralelismo e a contradição que envolve Estados, fronteiras e cooperação internacional.

Igualmente incisiva em sua crítica à globalização é a contribuição de um aclamado economista e analista internacional que recorre às experiências históricas para argumentar a respeito dos limites impostos pelo atual processo global no avanço dos países, em particular, os em desenvolvimento. Rodrik (2012) argumenta que os Estados - nações destes países passariam a sofrer sérias exceções inibidoras do desenvolvimento democrático quando freios aplicados nos investimentos sociais impedem avanços no bem-estar da sociedade. Um exemplo, que seria demostrado na quarta parte, é a privatização das empresas públicas e seus efeitos restritivos na expansão do emprego da mão-de-obra, devido não simplesmente ao processo de enxugamento do quadro pessoal visando alta lucratividade, mas em função da opção por novas técnicas de produção que abatem os custos da mão-de-obra.

A alusão aos efeitos redutivos da globalização no bem-estar social repercute com igual ou maior peso nos prospectos de melhoria nas condições dos direitos humanos com 
Hegemonia - Revista Eletrônica do Centro Universitário Euro-Americano

ISSN: 1809-1261

UNIEURO, Brasília, número 30, Julho-Dezembro de 2020, p. 104-131.

cidadania. Por exemplo, no Brasil, enquanto avançam as forças da globalização, a desigualdade social amplia-se ${ }^{10}$ e os direitos humanos sofrem sérios reveses. Nesse sentido, a globalização inibe a capacidade de transformação das instituições democráticas e das lideranças políticas uma vez que, com as operativas da primeira, a soberania se partilha entre a soberania nacional e os mecanismos do mercado agora teleguiados pelas forças externas e internas da globalização.

\section{DIREITOS HUMANOS E GLOBALIZAÇÃO}

Os direitos humanos, em princípio, versam sobre o direito de cada ser humano ser respeitado e valorizado, como indivíduo e ser social, com características particulares. Para Donnelly (2003), os direitos humanos são iguais e universais uma vez que, por se tratar de seres humanos como titulares de direitos indivisíveis e irreduzíveis, todos, independentes do grupo social que pertencem e do espaço geográfico que se encontram, gozem daqueles direitos historicamente construídos e atualmente afirmados em nível internacional, regional e nacional. Bobbio reconhece que "os direitos do homem nascem como direitos naturais universais, desenvolvem-se como direitos positivos particulares, para finalmente encontrarem sua plena realização como direitos positivos universais" (1992:30).

Os direitos humanos transbordam da história através de fenômenos despertadores tais como a revolta da corte de leão (1188), Magna Carta (1215) e Habeas Corpus (1678) e as revoluções no âmbito político, econômico e cultural (por exemplo, as revoluções inglesa, norte-americana e francesa) além das guerras e descobertas científicas mais relevantes. $\mathrm{Na}$ atualidade, os direitos humanos nasceram no pós Segunda Guerra Mundial, e são tidos interdependentes e juridicamente garantidos a nível internacional.

\footnotetext{
${ }^{10}$ A pesquisa Síntese de Indicadores Sociais (SIS) 2019, divulgada pelo Instituto Brasileiro de Geografia e Estatística (IBGE) mostra que enquanto o Produto Interno Bruto (PIB - a soma de todas as riquezas produzidas no país) cresceu 1,1\% em 2017 e 2018, após as quedas de 3,5\% em 2015 e 3,3\% em 2016, o rendimento dos $10 \%$ mais ricos da população subiu $4,1 \%$ em 2018 e o rendimento dos $40 \%$ mais pobres caiu $0,8 \%$, na comparação com 2017. Por mais detalhes, veja a publicação da Agência Brasil, de 06 Novembro 2019, intitulado "Extrema pobreza e desigualdade crescem há 4 anos" no Brasil.
} 
Hegemonia - Revista Eletrônica do Centro Universitário Euro-Americano

ISSN: 1809-1261

UNIEURO, Brasília, número 30, Julho-Dezembro de 2020, p. 104-131.

Daí dá para observar que os direitos humanos são na atualidade derivações históricas cuja consagração universal combinou-se com deduções ideológicas e teóricas, não sem adaptações nacionais.

$\mathrm{Na}$ Declaração Universal dos Direitos Humanos (DUDH) em 1948 pela Organização das Nações Unidas (ONU), proclamou-se como "ideal a atingir por todos os povos e todas as nações". Vários são os componentes como, por exemplo, pactos e convenções com desdobramentos regionais dos direitos humanos. Em geral, e mais relevante, destacam-se os pactos internacionais de direitos políticos, civis, econômicos e culturais. Tem sido o compromisso da ONU incluir entre os seus objetivos a promoção desses direitos e que Estados-nações ajam em colaboração com ela para promover a sua observância.

Todos os aspectos dos direitos humanos são importantes, mas para as propostas analíticas serão considerados aqueles direitos relativos ao conjunto dos pactos internacionais de Direitos Humanos. Os pactos internacionais suscetíveis de outorga pelas autoridades nacionais tratam dos "Direitos Civis e Políticos que constituem, historicamente, um meio de defesa de indivíduos ou grupos sociais contra os privilégios privados e os abusos do poder" e os pactos relativos aos "Direitos Econômicos, Sociais e Culturais [...]", tendo como "elemento comum ao conjunto de direitos neles declarados a proteção das classes ou grupos sociais desfavorecidos", isto é, "contra a dominação socioeconômica exercida pela minoria rica e poderosa" (COMPARATO, 2015, p. 350351). Nesse sentido, frisou Piovesan, os direitos humanos consistem em uma unidade indivisível, interdependente e inter-relacionada, capaz de conjugar o catálogo de direitos civis e políticos ao catálogo de direitos sociais, econômicos e culturais (2006, p. 18)

Um ponto crucial na caracterização da globalização é seu nexo com o desenvolvimento em sentido geral. Da mesma forma, os dois pactos internacionais acima apontados servem como base para um plano nacional e internacional mais amplo de direito ao desenvolvimento. Nesse sentido, Comparato (2015) recapitula que a resolução de 04 de dezembro de 1986, acatada pela Assembleia Geral das Nações Unidas, considera o desenvolvimento como "um amplo processo de natureza econômica, social e política", e aponta “a existência de sérios obstáculos' à sua sustentação e 'à realização dos seres 
Hegemonia - Revista Eletrônica do Centro Universitário Euro-Americano

ISSN: 1809-1261

UNIEURO, Brasília, número 30, Julho-Dezembro de 2020, p. 104-131.

humanos e dos povos" como um todo. Em específico, a Assembleia vê esses obstáculos’ como consistidos, inter alia, pela denegação dos direitos civis, políticos, econômicos, sociais e culturais', e entende 'que todos os direitos humanos e as liberdades fundamentais são indivisíveis e interdependentes (2015, p. 294). Salientou a reiteração da Assembleia de que se deve:

[...] dar igual atenção e considerar como urgente a implementação, promoção e proteção dos direitos civis, políticos, econômicos e sociais. Nos termos do art. $2^{\circ}$, alínea 3, dessa Resolução, os Estados têm o direito e o dever de formular políticas apropriadas para o desenvolvimento nacional, com objetivo de aumentar constantemente o bem-estar de toda população e de todos os indivíduos, na base de sua participação ativa, livre e consciente no desenvolvimento e na justa distribuição dos benefícios dele resultante. Os Estados têm a responsabilidade primordial de criar condições nacionais e internacionais favoráveis à realização do direito de desenvolvimento, o que implica o dever de colaboração de todos os Estados na eliminação dos obstáculos ao desenvolvimento (art. $3_{-}^{\circ}$ ).

De fato, a Comissão sobre Direitos Humanos das Nações Unidas tem reiterada, através de resoluções regulares sobre Globalização e seus Impactos no Pleno Gozo dos Direitos Humanos, a necessidade de a interconectividade mundial servir para promover direitos fundamentais. Por exemplo, além das resoluções da Assembleia Geral de 2000 e 2001, a Comissão de Direitos Humanos, pela resolução 2002/28, reafirma as resoluções 1999/59 de 28 de abril de 1999 e 2001/32 de 23 de abril 2001 e manifesta "preocupação pelo alargamento da distância entre os países desenvolvidos e em desenvolvimento que afeta negativamente o pleno gozo de direitos humanos, particularmente nos países em desenvolvimento". Daí reconhece que, "primeiro e mais importante, constituía a responsabilidade do Estado" para proteger e promover todos os direitos humanos mediante os possíveis impactos negativos da globalização ${ }^{11}$.

O entendimento que desponta das resoluções da ONU sobre direitos humanos, em especial dos mais destacados pactos internacionais, é que, considerando-se os possíveis efeitos socialmente danosos da globalização, os Estados, no âmbito tanto nacional quanto internacional, têm o dever inter alia de proteger e promover os direitos

\footnotetext{
${ }^{11}$ Comissão sobre Direitos Humanos 2002/28. Comissão sobre Direitos Humanos. 49a Reunião de 22 de abril de 2002.
} 
Hegemonia - Revista Eletrônica do Centro Universitário Euro-Americano

ISSN: 1809-1261

UNIEURO, Brasília, número 30, Julho-Dezembro de 2020, p. 104-131.

civis, políticos, econômicos, sociais e culturais através principalmente de decisões e ações políticas conscientes que favorecem o desenvolvimento humano.

Apesar das condutas idiossincráticas das elites políticas, fica difícil entender a forma que Estados-nações poderiam tomar e efetuar decisões favoráveis à proteção e promoção dos direitos humanos perante a erosão ou contração dos poderes territoriais do Estado pelas forças globalizantes, ou seja, de sua capacidade autônoma para acionar inter alia os instrumentos macroeconômicos e compensar os perdedores dos efeitos negativos da globalização.

No bojo dos direitos humanos com os cuidados do Estado para com sua proteção e promoção, destaca-se a cidadania. Por guardar características constitutivas dos direitos humanos, convém a abordagem mínima de Marshal (1977) que considera a cidadania o "direito de ter direito", comportando-se três tipos fundamentais de direitos pormenorizados. Direitos civis, integrando-se as liberdades de ir e vir, de imprensa, pensamento e fé e os direitos à propriedade, de fechar contratos validos, à justiça e gozo da igualdade formal. Há também os direitos do cidadão de participar na política, seja como ocupante de cargos públicos ou eleitor institucionalmente outorgado. Enfim, sobrevêm os direitos sociais, considerados nesse trabalho em termo experiencial no Brasil, e englobam o direito a um mínimo de bem-estar econômico com segurança e o direito de participar, por exemplo, na herança social e levar a vida de um ser civilizado de acordo com padrões que prevalecem na sociedade (MARSHAL 1977: 63-64).

Sobretudo, os direitos sociais têm implicações profundas para o indivíduo em sua vida pessoal e como integrante da sociedade. Ao abranger o direito de viver em condições socioeconômicas que conduzem ao bem-estar físico e intelectual do indivíduo, implica a capacidade de suprir os elementos vitais da vida tais como alimento, vestuário, moradia e educação. É nessa perspectiva que o acesso ao mercado, seja como agente consumidor, trabalhador ou produtor, passa a constituir uma dimensão indispensável para a proteção e promoção dos direitos humanos perante os efeitos indesejados da globalização. 
Hegemonia - Revista Eletrônica do Centro Universitário Euro-Americano

ISSN: 1809-1261

UNIEURO, Brasília, número 30, Julho-Dezembro de 2020, p. 104-131.

\section{BRASIL E DIREITOS HUMANOS MEDIANTE A GLOBALIZAÇÃO}

Não há como adentrar e avançar na análise dos efeitos da globalização sobre a capacidade do Estado para proteger, respeitar e promover direitos humanos, especialmente a cidadania, sem examinar a trajetória das políticas sociais, definidoras da reação de governos às mudanças contextuais nacionais e especialmente internacionais, frente ao advento impetuoso da globalização. Convém recapitular antes a existência perene de problemas estruturais, tais como exclusão social, desigualdade e pobreza da boa parte da sociedade brasileira. Além disso, diferentes governos, sob o mando de regimes políticos variados, têm reagido tipicamente e na medida do possível a esses problemas. No mínimo, os problemas expõem a persistência de mazelas internas e ensinam que nem toda sorte de problemas que afeta especialmente os direitos humanos e a cidadania decorrem singularmente da globalização. Daí, evidencia-se a exclusão social (que exige ação estatal pela sua correção) como fruto de uma industrialização que se iniciou nos anos 30 e se operou sem integração social consistente.

$\mathrm{Na}$ ausência de reformas corretivas, o processo de industrialização, pela sua natureza capital intensivo, deixou um contingente significativo da força de trabalho à margem tanto do mercado de trabalho quanto de consumo. As observações de Carvalho (2006), invocadas por Ederson (2016), mostram que o processo industrial no Brasil não foi acompanhado por "reformas civilizatórias do capitalismo" capazes de redistribuir a riqueza para promover a justiça social; reformar o espaço fundiário para minorar a concentração de propriedade da terra, recompor o sistema tributário para engendrar maior justiça fiscal e universalizar a proteção social (p. 58). Essa omissão fez alargar a estrutura de exclusão, em particular, nas regiões mais beneficiadas pelo desenvolvimento econômico, por conta do influxo de novos excluídos vindos de outras partes menos favorecidas pela modernização em curso (ibid).

Por outro lado, a ausência de reformas passou a exigir do Estado mais investimentos públicos destinados a prover serviços essenciais, tais como saúde e educação. O advento das grandes crises econômicas dos anos 80 e 90 com as transformações do capitalismo global tiveram desdobramentos políticos em diferentes 
Hegemonia - Revista Eletrônica do Centro Universitário Euro-Americano

ISSN: 1809-1261

UNIEURO, Brasília, número 30, Julho-Dezembro de 2020, p. 104-131.

países, inclusive Brasil, passando, ao menos, a agravar e complicar os problemas sociais. Isto é, postos em ação, as ideias neoliberais e o processo de globalização vêm afluindo no sentido de denegar a tênue capacidade do Estado para liderar com os problemas sociais preexistentes e emergentes.

Por extensão, ao globalizar o acesso ao mercado nacional, inspirado nos preceitos neoliberais, o Estado precisou ceder substancialmente sua soberania como agente tomador central de decisões econômicas e sociais sobre alocação de recursos no mercado de produção e consumo. A flexibilidade do mercado para possibilitar acesso maior da iniciativa privada significou na prática alienar as empresas públicas e retirar subsídios que juntos contribuíam para amenizar os problemas sociais e proteger os direitos da cidadania. No caso específico da privatização, essa tem levada à perda de postos de trabalho ou ao deslocamento disfuncional de empregos baseado na reestruturação técnica do processo produtivo que tenciona a eficiência econômica.

Pesquisas sobre a empregabilidade da mão-de-obra destituída pela privatização das empresas estatais mostram a enorme dificuldade, com a oneração de direitos sociais, em se recolocar no mercado formal de trabalho, seja no sentido de reproduzir a situação anterior ou pela renovação da própria força de trabalho. Nesse sentido, as observações de Oliveira et al (2007) são afirmativas dos impactos negativos da privatização na empregabilidade da mão-de-obra, pois, salvo dois trabalhadores, os 25 restantes que foram entrevistados numa pesquisa semiestruturada não conseguiram emprego no mercado formal. Para tanto, a privatização, sendo um corolário das ideias neoliberais e exigências da globalização para mudanças institucionais no âmbito do mercado e poder estatal, não vem favorecendo a realização de um dos direitos fundamentais mais vitais para a afirmação da dignidade humana - direito social e econômico.

Ademais, a ideia de que a privatização, que denota a transferência das empresas públicas à gestão privada orientada pelos princípios do livre mercado, conduzirá à eficiência na provisão dos serviços públicos, não está sendo tão realista quanto esperada. Ocorre atualmente em nível mundial a reestatização das empresas mediante a piora na provisão de bens ou serviços considerados estratégicos para os respectivos países. Setores estratégicos, tais como elétrico, telecomunicação etc., são objetos de desestatização para 
Hegemonia - Revista Eletrônica do Centro Universitário Euro-Americano

ISSN: 1809-1261

UNIEURO, Brasília, número 30, Julho-Dezembro de 2020, p. 104-131.

assegurar que os direitos elementares dos cidadãos sejam realizados de forma crescente pelo poder público onde os interesses públicos se solidificam naturalmente.

Segundo documentou o Jornal Brasil de Fato, uma pesquisa realizada em 2017 pela entidade holandesa Transnational Institute (Instituto Transnacional) revelou a ocorrência ao redor do mundo de pelo menos 884 casos de reestatização entre os anos de 2000 e 2017. No total, 835 empresas que haviam sido privatizadas foram remunicipalizadas e outras 49 foram renacionalizadas, principalmente na Europa, onde Alemanha e França respondem por 500 casos, na América do Norte, com os Estados Unidos da América respondendo por 67 desestatizações e outros países, como Japão, Argentina e a Índia, seguindo o mesmo caminho ${ }^{12}$.

Enquanto isso, diferentes governos brasileiros têm atuado constantemente para alienar mais empresas públicas com o intuito de arrecadar recursos financeiros e promover ajuste fiscal. Isto é, a preocupação pelo ajuste fiscal continua a preponderar sobre a prestação eficiente dos serviços públicos que enriqueçam os direitos fundamentais da cidadania. Enfim, sinaliza que o Estado brasileiro, supostamente, mais do que os outros, especialmente os supramencionados, ainda sente o peso sufocante das exigências neoliberais e das forças globalizantes, ao ponto de impedir que consiga atuar mais livremente em prol da defesa dos direitos fundamentais. Ademais, o advento dos governos conservadores, por vezes, denominados de extrema direita e amantes de retóricas nacionalistas, tende a estreitar mais ainda os caminhos da proteção e do respeito maior pelos direitos humanos e a cidadania constitutiva.

\section{CONCLUSÃO}

Nesse trabalho, procurou-se examinar as possíveis relações entre direitos humanos, cidadania e Estado mediante o ímpeto crescente da globalização. Para tanto, discorreu-se extensamente sobre a forma que a globalização, norteada pelo neoliberalismo e outorgada institucionalmente pelo Consenso de Washington, vem

\footnotetext{
${ }^{12}$ Cristiane Sampaio (2019). “Com piora no serviço, 884 empresas foram reestatizadas no mundo após
} privatização”. Brasil de Fato, Brasília, DF, 08 de Outubro de 2019. 
Hegemonia - Revista Eletrônica do Centro Universitário Euro-Americano

ISSN: 1809-1261

UNIEURO, Brasília, número 30, Julho-Dezembro de 2020, p. 104-131.

implicando em erosão ou contenção da capacidade do Estado para proteger e promover direitos fundamentais, inclusive os tocantes à cidadania como componente essencial. No caso brasileiro, acometido historicamente por problemas estruturais que beiram a desigualdade e exclusão social com a pobreza escorchante, o advento da globalização não encontrou terreno fértil para se arraigar e produzir resultados benéficos, mesmo relativamente, para toda sociedade.

A privatização, como processo e ação pública atrelada às ideias neoliberais e às forças globalizantes, ilustra como ocorre a contenção da soberania do Estado. Esse é induzido por aquelas forças a alienar as empresas públicas, a maioria considerada estratégica para o desenvolvimento econômico e social, para iniciativa privada, cuja conduta é orientada pela lógica do mercado.

Num contexto social em que prevaleça ampla assimetria na distribuição de renda, o acesso ao mercado, como núcleo de alocação de recursos, satisfação das necessidades e desenvolvimento social, redunda num ciclo vicioso, ou seja, se dá de forma exclusiva e consonante com a desigualdade social. No mínimo, exige a intervenção do Estado através dos investimentos públicos capazes de criar condições permissíveis ao gozo da liberdade individual de forma consonante com as ideias neoliberais e exigências neoliberais. Numa situação em que os tentáculos de articulação e alcance social do Estado estejam enfezados e impedidos, como foi verificado no trabalho mediante os instrumentos políticos e institucionais tais como Consenso de Washington e globalização, de atuarem em prol da sociedade, é inevitável que os direitos humanos com a cidadania não sejam prejudicados.

Apesar de que a ideia neoliberal não implique expressamente a proibição dos investimentos públicos sociais que posam beneficiar o mercado através, por exemplo, da educação e saúde que contribuem para empregabilidade, vem se verificando certa letargia na intervenção pública nessas áreas. À medida que a globalização, pragmaticamente impulsionada pelas ideias neoliberais e Consenso de Washington, avança, ocorre a contenção da soberania dos Estados-nações. Isto é, ao mesmo tempo em que não embarga totalmente investimentos totais do Estado na área social, as medidas ortodoxas baixadas pelo Consenso de Washington e adotadas pela maioria dos países em desenvolvimento, 
Hegemonia - Revista Eletrônica do Centro Universitário Euro-Americano

ISSN: 1809-1261

UNIEURO, Brasília, número 30, Julho-Dezembro de 2020, p. 104-131.

inclusive Brasil, lesam a capacidade daquela entidade, teoricamente com recursos de poder e autoridade superiores na sociedade, para voltar atenção aos investimentos sociais. Esses, além de dinamizar as operativas do mercado, promovam os direitos humanos e fortaleçam a cidadania.

Sem querer suprimir ou negar o potencial do livre mercado para alocar recursos de forma eficiente e servir como cerne para o desenvolvimento social, e fora as condutas excêntricas das elites governantes, não há como abjurar a importância estrategicamente interventora do Estado perante a globalização, especialmente nos contextos sociais permeados por graves problemas estruturais. Nesses contextos, o Estado não pode se omitir como sustentáculo e salvaguarda dos direitos fundamentais, sejam pela promoção da justiça ou, mais prementes, pelos investimentos públicos que locupletam as condições sociais.

\section{REFERÊNCIAS}

AXFORD, Barrie. "The Process of Globalization", in AXFORD, B et al (eds) Politics. London: Rutledge, 1997.

BRESSER-PEREIRA, Luiz Carlos (2009). "Assault on the State and on the Market: Neolibralism and Economic Theory”. Estudos Avançados (2)66, 2009.

BOBBIO, N. A era dos direitos. Rio de Janeiro: Campus, 1992.

CHANG, Ha-Joon. Kicking Away the Ladder. London: Anthem Press, 2003/2007.

COMPARATO, Fábio Konder. Afirmação Histórica dos Direitos Humanos. São Paulo: Saraiva, 2015.

EDERSON, Nascimento. "Urbanização, Globalização e Exclusão Social: Reflexões a partir do Caso Brasileiro". Revista Geográfica de América Central. (2)57, 2016, p. 4367

FRIEDMAN, Milton. Capitalismo e Liberdade. São Paulo: Nova Cultural, 1985.

GORE, C. "The Rise and Fall of the Washington Consensus as a Paradigm for Developing Countries". World Development: 28(5), 2000, p. 789-804 
Hegemonia - Revista Eletrônica do Centro Universitário Euro-Americano

ISSN: 1809-1261

UNIEURO, Brasília, número 30, Julho-Dezembro de 2020, p. 104-131.

HARVEY, David. A Brief History of Neoliberalism. Oxford: Oxford University Press, 2005.

HAYEK, Fredriech Von. O Caminho da Servidão. Rio de Janeiro, Top Books, 1990.

JAGDISH, N. Bhagwati. In: Defense of Globalization. London: Oxford University Press, 2007.

KOTZ, David M. Globalization and Neoliberalism. Department of Economics and Political Economy Research Institute, Thompson Hall, University of Massachusetts, Amherst, MA, U.S.A, 2000.

MARSHAL, Thomas H. A. Cidadania, Classe Social e Status. Rio de Janeiro, Zahar, 1977.

McGREW, A. "A Global Society”, in S. Hall, D. Held and A. McGrew (eds) Modernity and its Futures. Cambridge: Polity, 1992.

NEGRÃO, João José. Para Conhecer o Neoliberalismo. São Paulo: Publisher Brasil, 1998, p. 41-42

OliveirA, L. B. de, Wetzel, U.; CiARElli, C. G. P e CARDOSO, A. M. A Empregabilidade e o Destino Profissional de Trabalhadores Desligados de Empresas Estatais Privatizadas. I Encontro de Gestão de Pessoal e Relações de trabalho. Natal/RN 13 a 15 de junho de 2007.

PALMISANO, Samuel J. "The Globally Integrated Enterprise”. Foreign Affairs, (85)3, 2006.

BRESSER-PEREIRA, Luiz Carlos. "Assault on the State and on the Market: Neolibralism and Economic Theory”. Estudos Avançados (23)66, 2009.

PIOVESAN, F. "Direitos humanos: desafios da ordem internacional contemporânea". In: Piovesan, F. (Coord.). Direitos humanos. Curitiba: Juruá, 2006. p. 15-37.

RODRIK, Dani. The Globalization Paradox: Democracy and the Future of the World Economy, New York/London: W. W. Norton \& Company, 2012.

RODRIK, Dani. After Neoliberalism, What? Remarks at the BNDES Seminar on "New Paths of Development", Rio de Janeiro, September 12-13, 2002.

RODRIK, D. “Trading in Ilussions”. Foreign Policy, 123. 2001, p. 54-62

STIGLITZ, Joseph (2002) "Challenging the Washington Consensus". The Brown Journal of World Affairs. Winter/Springs Volume IX Issue 2, 2002. 
Hegemonia - Revista Eletrônica do Centro Universitário Euro-Americano

ISSN: 1809-1261

UNIEURO, Brasília, número 30, Julho-Dezembro de 2020, p. 104-131.

THORSTEIN, D. E. and LIE, A. What is Neoliberalism? Unpublished paper, Oslo: University of Oslo. Available at: http://folk.uio.no/daget/neoliberalism.pdf, Accessed 20 October 2020.

WILLIAMSON, John. "The Washington Consensus as Policy Prescription for Development". A lecture in the series "Practitioners of Development" delivered at the World Bank on January 13, 2004.

Recebido em: 15.04 .2020

Avaliado em: 20.06.2020

Aprovado em: 30.07.2020 